\title{
Route Planning with Dynamic Information from the EPLOS System
}

\author{
Michal Kłodawski, Marianna Jacyna, Rostislav Vasek, Piotr Klimek, Roland Jachimowski, Emilian Szczepański, Konrad Lewczuk
}

\begin{abstract}
The paper presents the problem of distribution route planning with dynamic information about sudden customers' needs. Particular attention was paid to dynamic vehicle route planning and its influence on the distance covered by a distribution vehicle. In the article, authors assume that the quick information about customers' sudden needs is transferred from the EPLOS tool data base. Authors analyze the available literature on transport route optimization and propose a solution to the problem of distribution among customers with sudden needs. In order to present the impact of quick information influence on the distribution route minimization, a simulation model of the vehicle routing problem was generated in the FlexSim environment.
\end{abstract}

Keywords: EPLOS; FlexSim; route minimization; route planning; VRP

\section{INTRODUCTION}

Transport is one of the key sectors of the economy in every country. Its importance for the movement of people and material goods seems to be indisputable.

Thus, the efficiency of the implementation of transport processes directly affects the duration of this process and its cost. This cost then also influences the prices of transported material goods.

In addition to the cost aspect, effective freight transport planning is key to satisfying the needs of the recipients of goods in a satisfactory manner in the shortest possible time and at the lowest possible price. Transport planning is not only organizing the right means of transport within a certain period, but also the proper organization of several processes accompanying the physical movement of goods. An example of such activities may be the planning of the route of cargo transport. Difficulties in the planning of the transport route should be seen mainly from the point of view of the lack of reliable information about the current conditions on the transport route (traffic jams, road sections, etc.) [1-3].

In addition to transport route planning, the performance of operational activities related to goods unloading can pose some problems. An example of this type of problems may be the availability of appropriate handling equipment enabling the unloading of vehicles at the recipient's end. Hence, both the knowledge of road conditions and the ability of shippers / recipients to load / unload goods can directly affect the efficiency of the implementation of the cargo transport process [4-6].

These situations most often make it difficult to plan full truck loads, where the goods from one supplier are delivered directly to one recipient. Delays on the transport route and difficulties in unloading vehicles at the advised time are typical problems that transport planners, dispatchers and forwarders must face every day.

The problems mentioned above increase in the case of goods delivered by a single vehicle from one / many senders to many recipients. In this situation, we are dealing with distribution, which is most often defined as the process of making products and services available to the recipients located in places other than service providers or production plants.

Therefore, fast and reliable information is crucial for proper transport planning. Unfortunately, the transfer of quick information faces many problems. Therefore, this article addresses the issue of access to quick information on customers' needs and its impact on distribution costs related to the length of vehicle routes. The article considers the vehicle routing problem with the dynamic information of the customers' needs. Such dynamic information can be downloaded from the EPLOS software (European Portal of Logistics Services) which is manufactured by the Warsaw University of Technology together with the CID International within the European Eureka Program.

\section{VEHICLE ROUTING PROBLEM WITH DYNAMIC INFORMATION}

The difficulties in cargo distribution planning result mainly from the many aspects that must be considered at the planning stage. These include, for example: limited load capacity of vehicles and their availability in time, time windows for the picking up and delivery of goods, many vehicles distributing cargo at the same time, variable traffic conditions, asymmetry of transport costs, etc. [1]. In literature, such a problem is called the Vehicle Routing Problem (VRP). This problem is development (by the abovementioned aspects such as load capacity, vehicle availability), one of the oldest optimization problems on networks, called the Traveling Salesman Problem (TSP), which consists of a salesman visiting each of the selected towns exactly once and returning to the town from which the journey began. The travel costs between each pair of locations are known $[7,8]$.

A traveling salesman should be planned in such a way that he can visit each place exactly once and the total cost of travel is as low as possible [7].

There are many different variations of the vehicle routing problem addressing the aspects of the reality mentioned above. Among the most common are the Capacitated VRP (CVRP), where each customer has a demand for a good and 
vehicles have a finite capacity; the VRP with Time Windows (VRPTW), where each customer must be visited during a specific timeframe; the VRP with the Pick-up and Delivery (PDP), where goods have to be picked-up and delivered in specific amounts at the vertices; and the Heterogeneous Fleet VRP (HVRP), where vehicles have different capacities.

In the era of a rapidly growing market economy, minimizing the costs of operating an enterprise is no longer the only indicator of its success in competition with the competitors. Very important is also the level of customer service, which depends on on-time deliveries and the ability to respond to sudden customer needs.

In the case of distribution, this issue is addressed by the dynamic vehicle routing problem (DyVRP), where the previously set route can be changed according to a sudden request for transport. That is why it is possible to quickly reshuffle the vehicle's route to minimize the unnecessary distance.

The DyVRP is not a new issue. For many years, scientists have been developing more and more new methods for solving the issue. The first publications dealing with the issue of DyVRP appeared as early the 1970s [9]. This publication concerned passenger transport, where passengers expressed their desire to travel without prior notice. This type of phenomenon is the most common example of dynamism in the DyVRP. This also applies to the transport of goods, where the demand for transport is already reported during the implementation of the vehicle's route. This aspect has been undertaken over the years by many scientists, including, [1, 10-14]. An element of such an emergency call may also be the performance of a service $[1,15-18]$. Another source of dynamism in the vehicle routing problem is the time of carrying out loading operations at shippers / recipients of cargo and the time of travel between successive loading / unloading points [1][19][20][21]. Some research also takes into account the possibility that the vehicle can simply break down during the route performance [22-24].

Since DyVRP belongs to the class of NP-hard problems (the optimum solution cannot be found in the acceptable time), its solution requires the use of heuristic algorithms such as: genetic, ant colony, particle swarm optimization, greedy, local search, simulated annealing, or Tabu Search. Additionally, agent programming, dynamic programming and simulation techniques are used to solve these types of problems [21, 25-34].

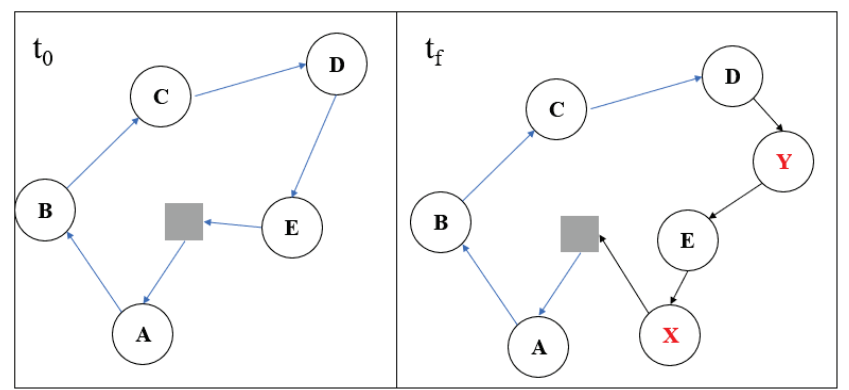

Figure 1 Example of a dynamic VRP
Schematically, the idea of the DyVRP is presented in Fig. 1. The first route designated in $t_{0}$ moment is contained of the points ABCDE. Suddenly in the moment $t_{\mathrm{f}}$, the route is extended by the points $\mathrm{X}$ and $\mathrm{Y}$. Because of that, the vehicle does not go from $\mathrm{D}$ to $\mathrm{E}$, but in the meantime serves $\mathrm{Y}$. Then after point $\mathrm{E}$, the vehicle visits $\mathrm{X}$ before it comes back to the base.

The optimization criterion for a DyVRP is usually the length of the route and the time it takes to complete it. However, other optimization criteria for this problem are e.g. customers' service level, number of requests served, transport provider capacity. The need to respond to dynamic customer requests also introduces the concept of response time: the customer can ask for service as soon as possible; in such cases, the main goal may be to minimize the delay between the arrival of the request and its handling.

\section{IT SYSTEMS SUPPORTING VEHICLE ROUTING WITH DYNAMIC INFORMATION}

Decision-making regarding the vehicle route must be done online, which can often be a compromise between the response time and the quality of the decision to fulfill that request. The longer the time it takes to find a solution for an emergency request, the less likely it is that a high level of response to that request will be met. Thus, ensuring a high level of customer service while responding quickly to his needs requires very quick access to information about his request. Quick access to logistics information requires the cooperation of both transport organizers and clients on transport services. Such cooperation is possible only thanks to the use of IT systems that connect logistics market participants.

An example of such a tool is the EPLOS (European Portal of Logistics Service) program, which provides access to customer data in real time, including the status of their demand for a given product. This program can be interfaced to the TMS (transport management system) tool of carriers and freight forwarders, as well as to the ERP (Enterprise Resource Planning) tool of customers. Thanks to that connection, the customer who cancels the delivery when the vehicle is already on the road has the option of informing the transport dispatcher about it. With the use of the tools for the planning of transport routes, the dispatcher can efficiently reroute the vehicle. The route planning tools must cooperate with the ITS (Inteligent Transport Systems) systems based on a combination of geolocation technologies with precise geographical location and increasingly more advanced equipment and software for data processing. The DyVRP mentioned above is usually implemented in the Advanced Fleet Management Systems (AFMS) tools used to manage a fleet of vehicle $[25,35]$. Thanks to this class of systems, it is possible to analyze and respond to customer requests ad hoc. The very important advantage of this type of systems is the possibility of route optimization or another parameter being the goal of real-time optimization. Nevertheless, these types of systems only allow cooperation with regular customers in a normally defined transport network that includes both the carrier and customers. 
In the case of more complex transport systems, the use of these tools can be troublesome due to the lack of access to quick information about the need to handle a sudden customer request. An example of this type of distribution systems will be the systems on a macro scale, where the carrier carrying out certain courses with loads is not aware of any customers who are outside its database and who could be served by this carrier.

Therefore, it is necessary to use the EPLOS system, which is a kind of a logistics database about the participants of the logistics market, both the customers interested in transport or some other logistics services as well as enterprises providing broadly understood logistics services. EPLOS is a system that gives the opportunity to share data on logistics services and gives access to this data to all users at the same time. Due to EPLOS, logistics market participants such as logistics operators, carriers and freight forwarders, who are currently downloading information about their destinations and contractors primarily from the online environment, can now access the quick information.

\section{CALCULATION EXAMPLE}

The information about the emerging demand for transport mentioned in the previous chapter is extremely important from the point of view of the minimization of costs associated with e.g. the loads distribution. Usually, a distribution vehicle obtains route information some time before the start of the route (the route is pre-planned by the planner). However, it may turn out that immediately after the start of the route, there is sudden information about the need to prioritize one of the recipients of cargo because of his change in the date of the delivery of cargo. Therefore, it is necessary to quickly re-plan the route.

The aim of this example is to show how the quick information about the sudden customer request transferred from the EPLOS to the carrier's TMS tool can influence the distance covered by the vehicle. It is assumed that the carrier's TMS tool has the routes optimization module. Because we don't have access to the carrier's TMS tool, we used the FlexSim simulation software to prepare the model of the Vehicle Routing Problem with dynamic information of the customer's needs. Therefore, in this case, FlexSim is just a software which allows the preparation of the VRP example and is not connected neither to the EPLOS nor to the carrier's TMS tool. The calculation example presented below allows determination of the impact of access to logistics information on the distances covered by distribution vehicles.

Examples of the use of FlexSim can be found in [36]. For the purpose of the study, a simulation model consisting of 6 customers was built. A fragment of this model is shown in Fig. 2. The numbers from 1 to 6 indicate the subsequent route points of the distribution vehicles.

It was assumed that the distribution route always starts and ends at point 1 . Moreover, it was assumed that right after the route starts, the driver can receive sudden information, that some recipients must be served as the first or last in the vehicle route. Such situations can appear when recipients change their original time windows for the delivery.

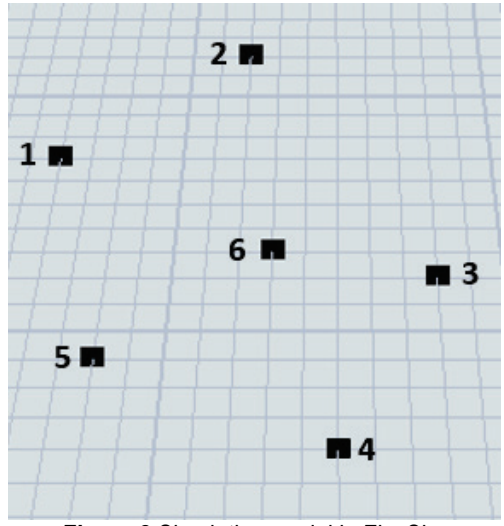

Figure 2 Simulation model in FlexSim

Using the FlexSim optimization module, the optimal vehicle route was determined for situations where there are no sudden customer's needs causing disruptions in the transport route. Searching for the minimum value via the heuristic algorithm implemented in FlexSim is shown in the Fig. 3.

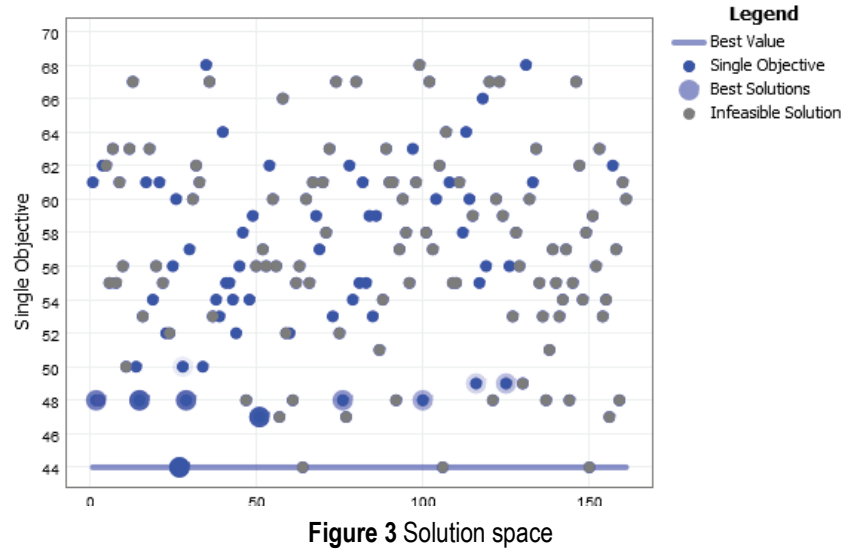

As a result, an optimal solution was obtained, according to the points shown in Fig. 2. The points from Fig. 2 were visited by the vehicle in the following order: 1-5-4-3-6-2-1. The obtained route was schematically presented in Fig. 4. The length of the route in this case was 44,51 units.

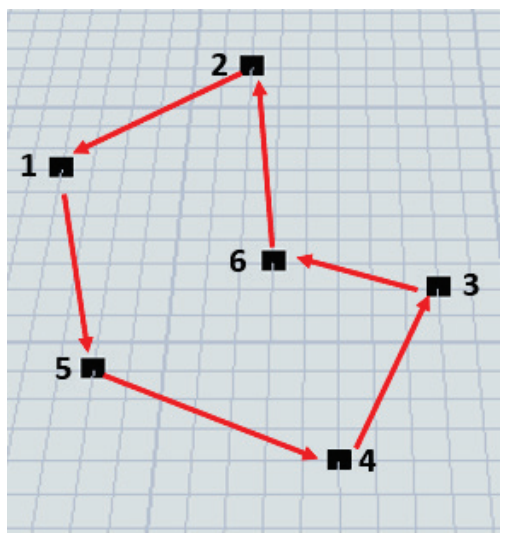

Figure 4 Calculation solution for the route planned in advance 
Consequently, various scenarios were analyzed assuming that individual points must be served as soon as the vehicle route begins or after the remaining points have been serviced (the driver receives information that the given point must be served as soon as possible or as the last one). The results of the calculations carried out are summarized in Tab. 1.

Table 1 Route optimization results

\begin{tabular}{|c|c|c|c|c|c|c|c|c|c|}
\hline \multicolumn{2}{|r|}{ Point number with a sudden need (notification)/notification type } & \multicolumn{7}{|c|}{ Service point order } & \multirow{2}{*}{$\frac{\text { Route length (units) }}{44.51}$} \\
\hline \multirow{2}{*}{2} & Service after the start of the route & 1 & 2 & 6 & 3 & 4 & 5 & 1 & \\
\hline & Service at the end of the route & 1 & 5 & 4 & 3 & 6 & 2 & 1 & 44.51 \\
\hline \multirow{2}{*}{3} & Service after the start of the route & 1 & 3 & 4 & 5 & 6 & 2 & 1 & 50.57 \\
\hline & Service at the end of the route & 1 & 2 & 6 & 5 & 4 & 3 & 1 & 50.56 \\
\hline \multirow{2}{*}{4} & Service after the start of the route & 1 & 4 & 5 & 6 & 3 & 2 & 1 & 52.77 \\
\hline & Service at the end of the route & 1 & 2 & 3 & 6 & 5 & 4 & 1 & 52.77 \\
\hline \multirow{2}{*}{5} & Service after the start of the route & 1 & 5 & 4 & 6 & 3 & 2 & 1 & 47.68 \\
\hline & Service at the end of the route & 1 & 2 & 6 & 3 & 4 & 5 & 1 & 44.51 \\
\hline \multirow{2}{*}{6} & Service after the start of the route & 1 & 6 & 5 & 4 & 3 & 2 & 1 & 48.24 \\
\hline & Service at the end of the route & 1 & 2 & 3 & 4 & 5 & 6 & 1 & 48.23 \\
\hline
\end{tabular}

"Service after the start of the route" indicates that the driver receives information that the given point must be served right after the service of point 1 .

"Service at the end of the route" indicates that the driver receives information after he begins with the route that the given point must be served as the last one.

The results presented in Tab. 1 clearly indicate that the sudden notification of transport demand affects the extension of the previously planned route of the vehicle. In the analyzed case, only the need for service after the start of the route and at the end of the route of point 2 did not cause the extension of the route presented in Fig. 5. Similar results were obtained for point 5 , which reported a need for its service at the end of the route. In other cases, the vehicle route was extended.

\section{CONCLUSIONS}

The problem of vehicle routing with dynamic information presented in the article is an important issue for minimizing the costs of transport as well as for maximizing the level of customer service. As emphasized in the article, planning the minimum route for freight transportation considering sudden notifications (need for transport) is not possible without access to quick information. This quick information can be transferred only with the use of IT systems that connect the customer with the carrier. The direct connection between customer and carrier is not always possible, which is why it is necessary to use tools such as EPLOS, which is a database that can connect the users of the logistics market (logistics market users can obtain information about each other, including the information of a sudden transport need). Such access to quick information about a sudden customer's need will allow, on the one hand, a quick response to the notification (ensuring a high level of customer service), and on the other hand, it will reserve more time to plan the route to minimize it.

The routing results presented with the use of FlexSim, which is just an environment for the preparation of the vehicle routing example, show that quick information positively influence the vehicles' routes and, in the end, also the transport costs.

\section{Acknowledgements}

The research has been carried out under the "European portal of logistics services" (EPLOS) project, funded by the National Centre for Research and Development of Poland.

\section{Notice}

The paper will be presented at MOTSP 2020 International Conference Management of Technology - Step to Sustainable Production, which will take place from $30^{\text {th }}$ September $-2^{\text {nd }}$ October 2020 in Bol, island Brač (Croatia). The paper will not be published anywhere else.

\section{REFERENCES}

[1] Jacyna, M. \& Żak, J. (2016). Simulation models in testing reliability of transport process. Journal of KONBiN, 37(1), 203230. https://doi.org/10.1515/jok-2016-0010

[2] Jacyna M, Izdebski, M., Szczepanski, E., \& Golda, P. (2018). The task assignment of vehicles for a production company. Symmetry-Basel, 11(10), 1-19. https://doi.org/10.3390/sym10110551

[3] Izdebski, M. (2014). The use of heuristic algorithms to optimize the transport issues on the example of municipal services companies. Archives of Transport, 29(1), 27-36. https://doi.org/10.5604/08669546.1146961

[4] Jacyna, M. \& Szczepanski, E. (2013). Holistic approach to the ecological cargo distribution in urban areas with the use of multi-modal transport. WIT Transactions on the Built Environment, 130, 53-65. https://doi.org/10.2495/UT130051

[5] Jachimowski, R. \& Zak, J. (2013). Vehicle routing problem with heterogeneous customers demand and external transportation costs. Journal of Traffic and Logistics Engineering, 1(1), 46-50. https://doi.org/10.12720/jtle.1.1.46-50

[6] He, P. \& Li, J. (2018). Vehicle routing problem with partly simultaneous pickup and delivery for the cluster of small and medium enterprises. Archives of Transport, 45(1), 35-42. https://doi.org/10.5604/01.3001.0012.0940

[7] Lewczuk, K., Żak, J., Pyza, D., \& Jacyna-Gołda, I. (2013). Vehicle routing in urban area-environmental and technological determinants, Urban Transport XIX, Ed. CA Brebbia (WIT Transactions on The Built Environment, Vol. 130, 373-384). https://doi.org/10.2495/UT130291 
[8] Izdebski, M. \& Jacyna, M. (2018). The Organization of Municipal Waste Collection: The Decision Model. Rocznik Ochrona Środowiska, 20.

[9] Wilson, N. \& Colvin, N. (1977). Computer control of the Rochester dial-a-ride system. Technical Report R77-31, Dept. of Civil Engineering, Massachusetts Institute of Technology, Cambridge, Massachusetts.

[10] Goel, A. \& Gruhn, V. (2008). A general vehicle routing problem. European Journal of Operational Research, 191(3), 650-660, https://doi.org/10.1016/j.ejor.2006.12.065

[11] Hvattum, L. M., Lokketangen, A., \& Laporte, G. (2007). A branch-and-regret heuristic for stochastic and dynamic vehicle routing problems. Networks, 49(4), 330-340. https://doi.org/10.1002/net.20182

[12] Ichoua, S., Gendreau, M., \& Potvin, J.-Y. (2006). Exploiting knowledge about future demands for real-time vehicle dispatching. Transportation Science, 40(2), 211-225. https://doi.org/10.1287/trsc.1050.0114

[13] Lorini, S., Potvin, J.-Y., \& ZuUerey, N. (2011). Online vehicle routing and scheduling with dynamic travel times. Computers \& Operations Research, 38(7), 1086-1090. https://doi.org/10.1016/j.cor.2010.10.019.

[14] Tagmouti, M., Gendreau, M., \& Potvin, J.-Y. (2011). A dynamic capacitated arc routing problem with time-dependent service costs. Transportation Research Part C: Emerging Technologies, 19(1), 20-28. https://doi.org/10.1016/j.trc.2010.02.003

[15] Beaudry, A., Laporte, G., Melo, T., \& Nickel, S. (2010). Dynamic transportation of patients in hospitals. OR Spectrum, 32, 77-107, https://doi.org/10.1007/s00291-008-0135-6

[16] Bent, R. \& Van Hentenryck, P. (2005). Online stochastic and robust optimization. In Maher, M., editor, Advances in Computer Science - ASIAN 2009, volume 3321 of Lecture Notes in Computer Science, pages 286-300. Springer Berlin / Heidelberg. https://doi.org/10.1007/978-3-540-30502-6_21

[17] Thomas, B. W. (2007). Waiting strategies for anticipating service requests from known customer locations. Transportation Science, 41(3), 319-331. https://doi.org/10.1287/trsc.1060.0183

[18] Attanasio, A., Bregman, J., Ghiani, G., \& Manni, E. (2007). Real-time Weet management at Ecourier Ltd. In Zeimpekis, V., Tarantilis, C. D., Giaglis, G. M., and Minis, I., editors, Dynamic Fleet Management, volume 38 of Operations Research/Computer Science Interfaces, chapter 10, pages 219238. Springer US. https://doi.org/10.1007/978-0-387-71722-7_10

[19] Barcelo, J., Grzybowska, H., \& Pardo, S. (2007). Vehicle routing and scheduling models, simulation and city logistics. In Zeimpekis, V., Tarantilis, C. D., Giaglis, G. M., and Minis, I., editors, Dynamic Fleet Management, vol. 38 of Operations Research/Computer Science Interfaces, pages 163-195. Springer US. https://doi.org/10.1007/978-0-387-71722-7_8

[20] Chen, H.-K., Hsueh, C.-F., \& Chang, M.-S. (2006). The realtime time-dependent vehicle routing problem. Transportation Research Part E: Logistics and Transportation Review, 42(5), 383-408. https://doi.org/10.1016/j.tre.2005.01.003.

[21] Güner, A. R., Murat, A., \& Chinnam, R. B. (2012). Dynamic routing under recurrent and nonrecurrent congestion using realtime its information. Computers \& Operations Research, 39(2), 358-373. https://doi.org/10.1016/j.cor.2011.04.012

[22] Li, J.-Q., Mirchandani, P. B., \& Borenstein, D. (2009a). A lagrangian heuristic for the real-time vehicle rescheduling problem. Transportation Research Part E: Logistics and Transportation Review, 45(3), 419-433. https://doi.org/10.1016/j.tre.2008.09.002
[23] Mu, Q., Fu, Z., Lysgaard, J., \& Eglese, R. (2011). Disruption management of the vehicle routing problem with vehicle breakdown. Journal of the Operational Research Society, 62(4), 742-749. https://doi.org/10.1057/jors.2010.19

[24] Chen, S., Chen, R., \& Gao, J. (2017). A monarch butterfly optimization for the dynamic vehicle routing problem. Algorithms, 10(3), 107. https://doi.org/10.3390/a10030107

[25] Ghannadpour, S. F., Noori, S., Tavakkoli-Moghaddam, R., \& Ghoseiri, K. (2014). A multi-objective dynamic vehicle routing problem with fuzzy time windows: Model, solution and application. Applied Soft Computing, 14, 504-527. https://doi.org/10.1016/j.asoc.2013.08.015

[26] Jacyna-Gołda, I. \& Izdebski, M. (2017, September). The Warehouse Location Problem in the Context of Vehicle Routing Problem in the Production Companies. In Scientific and Technical Conference Transport Systems Theory and Practice (pp. 50-62). Springer, Cham. https://doi.org/10.1007/978-3-319-64084-6_5

[27] Klodawski, M., Jachimowski, R., Jacyna-Golda, I., \& Izdebski, M. (2018). Simulation analysis of order picking efficiency with congestion situations. International Journal of Simulation Modelling, 17(3), 431-443. https://doi.org/10.2507/IJSIMM17(3)438

[28] Kuo, R. J., Wibowo, B. S., \& Zulvia, F. E. (2016). Application of a fuzzy ant colony system to solve the dynamic vehicle routing problem with uncertain service time. Applied Mathematical Modelling, 40(23-24), 9990-10001. https://doi.org/10.1016/j.apm.2016.06.025

[29] Pillac, V., Gendreau, M., Guéret, C., \& Medaglia, A. L. (2013). A review of dynamic vehicle routing problems. European Journal of Operational Research, 225(1), 1-11. https://doi.org/10.1016/j.ejor.2012.08.015

[30] Psaraftis, H. N., Wen, M., \& Kontovas, C. A. (2016). Dynamic vehicle routing problems: Three decades and counting. Networks, 67(1), 3-31. https://doi.org/10.1002/net.21628

[31] Jachimowski, R. \& Zak, J. (2013). Vehicle routing problem with heterogeneous customers demand and external transportation costs. Journal of Traffic and Logistics Engineering, 1(1), 46-50. https://doi.org/10.12720/jtle.1.1.46-50

[32] Szczepański, E. \& Jachimowski, R. (2013). Simulation analysis of vehicle routing problem solution, w: Feliks Jerzy (red.): CLC 2013: Carpathian Logistics Congress - Congress Proceedings, 2014, pp. 446-452. TANGER Ltd., Ostrava, ISBN 978-80-87294-53-6.

[33] Szczepański, E., Żak, J., Jacyna-Gołda, I., \& Murawski, J. (2017). Simulation support of freight delivery schedule in urban areas. Procedia Engineering, 187, 520-525. https://doi.org/10.1016/j.proeng.2017.04.409

[34] Yang, Z., van Osta, J. P., van Veen, B., van Krevelen, R., van Klaveren, R., Stam, A., ... \& Emmerich, M. (2017). Dynamic vehicle routing with time windows in theory and practice. Natural computing, 16(1), 119-134. https://doi.org/10.1007/s11047-016-9550-9

[35] Crainic, T. G., Gendreau, M., \& Potvin, J.-Y. (2009). Intelligent freight-transportation systems: Assessment and the contribution of operations research. Transportation Research Part C: Emerging Technologies, 17(6), 541-557. https://doi.org/10.1016/j.trc.2008.07.002

[36] Jachimowski, R., Szczepański, E., Kłodawski, M., Markowska, K., \& Dąbrowski, J. (2018). Selection of a container storage strategy at the rail-road intermodal terminal as a function of minimization of the energy expenditure of transshipment devices and $\mathrm{CO}_{2}$ Emissions. Rocznik Ochrona Środowiska, 20. 


\section{Authors' contacts:}

Michał Kłodawski, PhD.

(Corresponding author)

Warsaw University of Technology,

Koszykowa 75 Street, 00-662 Warsaw, Poland

e-mail: mkloda@wt.pw.edu.pl

Marianna Jacyna, Prof.

Warsaw University of Technology,

Koszykowa 75 Street, 00-662 Warsaw, Poland

e-mail: maja@wt.pw.edu.pl

Rostislav Vasek, Ing.

CID International,

Dr. Milady Horákové 1200/27A, 77900 Olomouc, Czech Republic

e-mail: rvasek@cid.cz

Piotr Klimek, MSc.

Oltis Polska,

Króla Kazimierza Wielkiego 21/203A Street, 32-300 Olkusz, Poland

e-mail: info@oltis.pl

Roland Jachimowski, PhD

Warsaw University of Technology,

Koszykowa 75 Street, 00-662 Warsaw, Poland

e-mail: rjach@wt.pw.edu.pl

Emilian Szczepański, PhD

Warsaw University of Technology,

Koszykowa 75 Street, 00-662 Warsaw, Poland

e-mail: eszczepanski@wt.pw.edu.pl

Konrad Lewczuk, PhD

Warsaw University of Technology,

Koszykowa 75 Street, 00-662 Warsaw, Poland

e-mail: kle@wt.pw.edu.pl 